\title{
Reactive evaporation of SiOx films for passivation of GaN high-electron-mobility transistors
}

DOI:

10.1016/j.jpcs.2018.12.021

\section{Document Version}

Accepted author manuscript

Link to publication record in Manchester Research Explorer

\section{Citation for published version (APA):}

Zhu, G., Liang, G., Zhou, Y., Chen, X., Xu, X., Feng, X., \& Song, A. (2019). Reactive evaporation of SiOx films for passivation of GaN high-electron-mobility transistors. Journal of Physics and Chemistry of Solids, 129, 54-60. https://doi.org/10.1016/j.jpcs.2018.12.021

\section{Published in:}

Journal of Physics and Chemistry of Solids

\section{Citing this paper}

Please note that where the full-text provided on Manchester Research Explorer is the Author Accepted Manuscript or Proof version this may differ from the final Published version. If citing, it is advised that you check and use the publisher's definitive version.

\section{General rights}

Copyright and moral rights for the publications made accessible in the Research Explorer are retained by the authors and/or other copyright owners and it is a condition of accessing publications that users recognise and abide by the legal requirements associated with these rights.

\section{Takedown policy}

If you believe that this document breaches copyright please refer to the University of Manchester's Takedown Procedures [http://man.ac.uk/04Y6Bo] or contact uml.scholarlycommunications@manchester.ac.uk providing relevant details, so we can investigate your claim.

\section{OPEN ACCESS}




\title{
Reactive evaporation of $\mathrm{SiO}_{\mathrm{x}}$ films for passivation of $\mathrm{GaN}$ high-electron-mobility transistors
}

\author{
Gengchang Zhu $u^{\mathrm{a}}$, Guangda Liang ${ }^{\mathrm{a}}$, Yang Zhou ${ }^{\mathrm{b}}$, Xiufang Chen $^{\mathrm{c}}$, Xiangang $\mathrm{Xu}^{\mathrm{c}, *}$, Xianjin Feng ${ }^{\mathrm{a}, *}$ and \\ Aimin Song $g^{\mathrm{a}, \mathrm{c}, \mathrm{d}, *}$ \\ ${ }^{\text {a }}$ Center of Nanoelectronics and School of Microelectronics, Shandong University, Jinan 250100, China. \\ ${ }^{\mathrm{b}}$ Microsystem and Terahertz Research Center, China Academy of Engineering Physics, Chengdu 610200, China. \\ ${ }^{\mathrm{c}}$ State Key Laboratory of Crystal Materials, Shandong University, Jinan 250100, China. \\ ${ }^{\mathrm{d}}$ School of Electrical and Electronic Engineering, University of Manchester, Manchester M13 9PL, United Kingdom.
}

\begin{abstract}
The surface passivation effects of silicon suboxide $\left(\mathrm{SiO}_{\mathbf{x}}\right)$ prepared by the reactive evaporation of silicon monoxide in oxygen atmosphere on the performance of AIGaN/AIN/GaN high-electron-mobility transistors (HEMTs) have been investigated. $\mathrm{SiO}_{\mathrm{x}}$ films with different oxygen contents $(1.10 \leq x \leq 1.71)$ and root-mean-square $(\mathrm{RMS})$ roughnesses $(0.55 \leq \mathrm{RMS} \leq 1.01 \mathrm{~nm})$ were prepared under residual pressures from $1 \times 10^{-6}$ to $6 \times 10^{-4}$ Torr. Hall measurements revealed obvious increases in the product of sheet carrier concentration and electron mobility after the passivation. Accordingly, increases in drain current and transconductance were observed for all the $\mathrm{SiO}_{\mathbf{x}}$ passivated HEMTs. Both the gate and drain leakage currents first decreased and then increased with the increase of oxygen content. The lowest gate leakage current was observed in the devices with $\mathrm{SiO}_{1.23}$ passivation, and it was almost 20 times lower than that of the unpassivated devices. The same devices also exhibited the lowest current collapse and off-state drain current. The variations in leakage currents as a function of the residual pressure were found to correlate with the surface roughness of the passivation layer. Finally, the breakdown voltage of the $\mathrm{SiO}_{1.23} \mathrm{Passivated}_{\mathrm{HEMTs}}$ increased to $151 \mathrm{~V}$, up from $99 \mathrm{~V}$ in unpassivated devices.
\end{abstract}

Keywords - reactive evaporation, $\mathrm{SiO}_{\mathrm{x}}$, passivation, GaN, HEMTs

\section{INTRODUCTION}

$\mathrm{G}_{\mathrm{b}}$ AN high-electron-mobility transistors (HEMTs) have been extensively investigated for high-power, highfrequency, and high-voltage applications due to their wide band gap, high thermal stability, high electron saturation velocity, and high breakdown electrical field[1-4]. However, there are still some limitations to commercial applications of $\mathrm{GaN}$ HEMTs. For instance, the current collapse effect resulting from the surface trapping could have a severe effect on the device performance [5]. Surface passivation is a very effective solution to alleviate drain current collapse by reducing surface traps [6-8]. Therefore, strong interest has been directed towards development of passivation materials and processes in the past decade. Besides conventional passivation materials such as $\mathrm{SiN}_{\mathrm{x}}$ and $\mathrm{SiO}_{2}$ [9], other dielectrics like $\mathrm{SiON}$ [9, 10], $\mathrm{Al}_{2} \mathrm{O}_{3}$ [11-14], $\mathrm{HfO}_{2}$ [15-17], $\mathrm{Sc}_{2} \mathrm{O}_{3}$ [18, 19], and $\mathrm{MgO}[18,20]$ prepared by plasma-enhanced chemical-vapour deposition (PECVD), sputtering, atomic-layer deposition (ALD), molecular-beam epitaxy (MBE) etc. have been studied. However, controversial results of the passivation effects have been published, probably resulting from different material properties and deposition processes. For example, an increase [21] as well as a decrease $[9,22]$ in the gate leakage current $\left(I_{\text {gleak }}\right)$ after $\mathrm{SiN}_{\mathrm{x}}$ passivation were reported. Large $I_{\text {gleak }}$ is a main limiting factor in high power and high voltage applications of GaN HEMTs.

*Corresponding authors: Xianjin Feng (e-mail: xianjinfeng@sdu.edu.cn), Xiangang $\mathrm{Xu}$ (e-mail: $\mathrm{xxu@sdu.edu.cn)} \mathrm{and} \mathrm{Aimin} \mathrm{Song} \mathrm{(email:}$ A.Song@manchester.ac.uk)
It has been demonstrated that the $I_{\text {gleak }}$ is closely related to the off-state breakdown voltage $\left(V_{\mathrm{br}}\right)$ of HEMT devices [23].

PECVD and other above-mentioned techniques have common limitations of higher equipment cost and/or longer processing duration as compared with thermal evaporation. Furthermore, in commonly used PECVD and sputtering techniques, plasma damage or shallow ion implantation may occur during the device fabrication process, which could have detrimental effects on the electrical characteristics of $\mathrm{GaN}$ HEMTs $[24,25]$. Due to the simple technique and being free of ion damage, thermally evaporated $\mathrm{SiO}$ has been used in many devices such as In-Ga-Zn-O thin-film transistors [24], self-switching diodes [26] and graphene field-effect transistors [27]. Recently, we have demonstrated that thermally evaporated $\mathrm{SiO}$ is a very promising passivation material for GaN HEMTs [28]. Besides enhancements in drain current and transconductance, $I_{\text {gleak }}$ and off-state drain current $\left(I_{\text {off }}\right)$ of the $\mathrm{SiO}$ passivated HEMTs decreased by more than two orders of magnitude compared with the devices passivated with PECVD grown $\mathrm{SiN}_{\mathrm{x}}$. Moreover, due to the reduction of leakage current [23], the $\mathrm{SiO}$ passivation enabled about two times higher breakdown voltage than in the device with standard $\mathrm{SiN}_{\mathrm{x}}$ passivation.

Oxygen content in $\mathrm{SiO}_{\mathrm{x}}$ films could be manipulated by changing the oxygen flow rate during the thermal evaporation of $\mathrm{SiO}$ [29]. This may have strong influence on the performance of $\mathrm{SiO}_{x}$ passivated GaN HEMTs, which is so far not studied. In this work, we investigate the surface passivation effect of $\mathrm{SiO}_{x}$ films reactively evaporated under different oxygen pressures on the performance of AlGaN/AIN/GaN HEMTs. Room- temperature Hall effect measurements, $\mathrm{SiO}_{\mathrm{x}}$ film morphology and stoichiometry 
characterisations, and current-voltage measurements of HEMT devices with and without the passivation are performed. A large number of $\mathrm{SiO}_{\mathrm{x}}$ film properties and HEMT device performance parameters are found to closely depend on the residual oxygen pressure during the reactive evaporation, such as the $\mathrm{SiO}_{\mathrm{x}}$ film roughness, $\mathrm{SiO}_{\mathrm{x}}$ film stoichiometry, HEMT on-state and off-state drain currents, transconductance, etc. Apart from the improvements in drain current and transconductance, our results show that passivation with $\mathrm{SiO}_{1.23}$ film resulted in a 20 times decrease in both $I_{\text {gleak }}$ and $I_{\text {off }}$ as well as a large increase in $V_{\text {br }}$ by $52 \mathrm{~V}$. The study therefore demonstrates that reactively evaporated $\mathrm{SiO}_{\mathrm{x}}$ film may provide very effective surface passivation for GaN HEMTs, particularly for high power and noise sensitive applications.

\section{DEVICE FABRICATION}

The schematic cross-sectional view of our fabricated $\mathrm{AlGaN} / \mathrm{AlN} / \mathrm{GaN}$ HEMTs with $\mathrm{SiO}_{\mathrm{x}}$ passivation is shown in Fig. 1. The source-drain spacing $\left(L_{\mathrm{sd}}\right)$ and gate-drain spacing $\left(L_{g d}\right)$ of the devices are 13 and $6 \mu \mathrm{m}$, respectively. The gate length $\left(L_{\mathrm{g}}\right)$ is $2 \mu \mathrm{m}$ and gate width $\left(W_{\mathrm{g}}\right)$ is $100 \mu \mathrm{m}$. The AlGaN/AlN/GaN heterostructure was grown on a 2-in.-diameter $\mathrm{SiC}$ substrate by a metal-organic chemical-vapour deposition (MOCVD) system. The epi-layers used in this study consist of a $100 \mathrm{~nm}$ AlN nucleation layer, a $1.8 \mu \mathrm{m}$ semi-insulating GaN layer, a $1 \mathrm{~nm}$ AlN interlayer and a $25 \mathrm{~nm}$ unintentionally doped $\mathrm{AlGaN}$ layer with an $\mathrm{Al}$ content of $22 \%$. Hall effect measurements at room temperature revealed a sheet carrier density $\left(n_{\mathrm{s}}\right)$ of $9.4 \times 10^{12} \mathrm{~cm}^{-2}$, a sheet resistance of $290 \Omega / \mathrm{Sq}$ and a carrier mobility $\left(\mu_{\mathrm{n}}\right)$ of 1850 $\mathrm{cm}^{2} \cdot \mathrm{V}^{-1} \cdot \mathrm{s}^{-1}$. The device fabrication process started with mesa isolation using $\mathrm{BCl}_{3} / \mathrm{Cl}_{2}$ plasma-based inductively coupled plasma reactive ion etching (ICP-RIE). The source and drain Ohmic contacts (Ti/Al/Ni/Au: 30/150/50/80 nm) were formed by electron-beam evaporation, and subsequently alloyed by rapid thermal annealing at $880^{\circ} \mathrm{C}$ for $50 \mathrm{~s}$ in nitrogen ambient. The contact resistivity was $3.0 \times 10^{-6} \Omega \cdot \mathrm{cm}^{2}$ measured using the transmission-line method at room temperature. The Schottky gate (Ni/Au: 50/80 nm) was also achieved using electron-beam evaporation. Finally, a $100 \mathrm{~nm} \mathrm{SiO}$ x passivation layer was deposited on the surface of the HEMTs by reactive thermal evaporation in low-pressure oxygen. All device patterns were defined by conventional photo-lithography and lift-off processes. Before the metal or $\mathrm{SiO}_{\mathrm{x}}$ film depositions, the $\mathrm{AlGaN}$ surface was cleaned by $\mathrm{HCl}$ solution.

The $\mathrm{SiO}_{\mathrm{x}}$ films were obtained by thermal evaporation of high purity $(99.99 \%) \mathrm{SiO}$ powders in a tungsten boat. The deposition rate was monitored by a quartz microbalance. The thickness of $\mathrm{SiO}_{\mathrm{x}}$ films was $100 \mathrm{~nm}$, deposited at a constant rate of $2 \AA / s$. The background pressure in the thermal evaporator chamber was $1 \times 10^{-6}$ Torr if no oxygen was intentionally introduced. The residual pressure increased when introducing a small amount of oxygen gas. Five samples were fabricated under different residual pressures. Sample A was deposited at $1 \times 10^{-6}$ Torr without intentionally introduced oxygen. The other samples were produced in oxygen ambient with sample B at $1 \times 10^{-5}$ Torr, sample C at $5 \times 10^{-5}$ Torr, sample D at $1 \times 10^{-4}$ Torr, and sample E at $6 \times 10^{-4}$ Torr, respectively. The surface morphology and roughness of the $\mathrm{SiO}_{\mathrm{x}}$ films were studied by a Benyuan CSPM5500 atomic-force microscope (AFM). The oxygen content (x) of the $\mathrm{SiO}_{\mathrm{x}}$ films was determined by an Energy Dispersive X-ray Spectroscope (EDS) attached to an FEI Nova NanoSEM450 scanning electron microscope (SEM). Hall measurements were performed using the Van der Pauw technique at room temperature. The DC and pulsed characteristics of the HEMTs were measured using a Keysight (Agilent) B2902A Precision Source/Measurement Unit at room temperature.

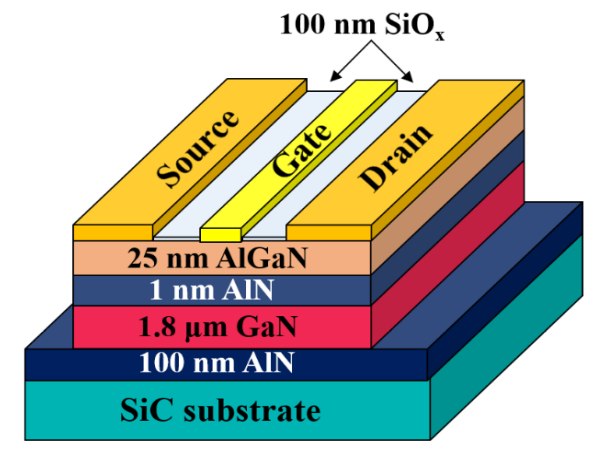

Fig. 1. Schematic cross-section of AlGaN/AlN/GaN HEMTs with $\mathrm{SiO}_{x}$ passivation.

\section{RESUltS AND DisCUSSION}

To clarify the influence of residual pressure on the film properties, we first characterised the $\mathrm{SiO}_{\mathrm{x}}$ films deposited under different pressures. The surface morphologies obtained by AFM are shown in Fig. 2 and the roughness values are given in Table I, which summarises the main measurement results of our study. The AFM scan area is $5 \mu \mathrm{m} \times 5 \mu \mathrm{m}$. The $\mathrm{SiO}_{\mathrm{x}}$ film evaporated with no additional oxygen (sample A) has a smooth surface with a root-mean-square (RMS) roughness of $0.55 \mathrm{~nm}$. This value is similar to that of thermally oxidised $\mathrm{SiO}_{2}$ [30] but smaller than typical sputtered $\mathrm{SiO}_{2} \quad[31]$ or $\quad$ PECVD 


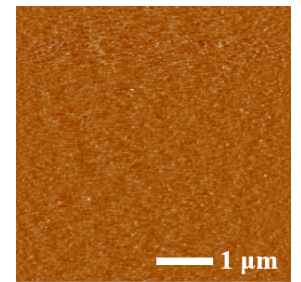

(a)

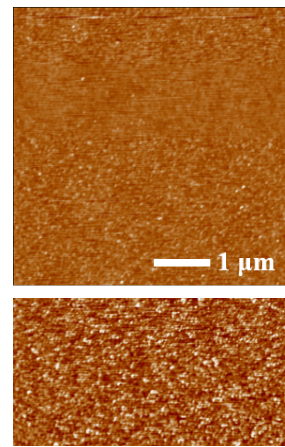

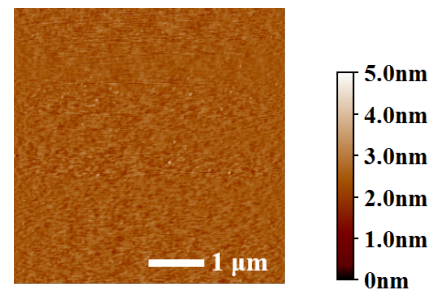

(b)
TABLE I

SUMMARY OF THE EXPERIMENTAL RESULTS

\begin{tabular}{|c|c|c|c|c|c|c|}
\hline Sample & $\begin{array}{c}\text { Un- } \\
\text { passivated }\end{array}$ & A & B & $\mathrm{C}$ & $\mathrm{D}$ & $\mathrm{E}$ \\
\hline Pressure (Torr) & $\mathrm{N} / \mathrm{A}^{\mathrm{a}}$ & $1 \times 10^{-6}$ & $1 \times 10^{-5}$ & $5 \times 10^{-5}$ & $1 \times 10^{-4}$ & $6 \times 10^{-4}$ \\
\hline $\begin{array}{c}n_{\mathrm{s}} \\
\left(10^{12} \mathrm{~cm}^{-2}\right)\end{array}$ & 9.4 & 10.8 & 10.7 & 9.8 & 9.9 & 10.3 \\
\hline $\begin{array}{c}\mu_{\mathrm{n}} \\
\left(\mathrm{cm}^{2} \cdot \mathrm{V}^{-1} \cdot \mathrm{s}^{-1}\right)\end{array}$ & 1850 & 1795 & 1810 & 1818 & 1815 & 1810 \\
\hline $\begin{array}{l}\text { Oxygen content } \\
\text { (x) }\end{array}$ & N/A & 1.10 & 1.23 & 1.41 & 1.54 & 1.71 \\
\hline RMS (nm) & $\mathrm{N} / \mathrm{A}$ & 0.55 & 0.56 & 0.62 & 0.83 & 1.01 \\
\hline $\begin{array}{c}\text { Current collapse } \\
(\%)\end{array}$ & 28.2 & 13.6 & 11.5 & 20.2 & 25.7 & 28.1 \\
\hline$g_{\mathrm{m}}\left(\mathrm{mS} \cdot \mathrm{mm}^{-1}\right)$ & 116 & 137 & 139 & 133 & 123 & 120 \\
\hline$V_{\text {th }}(\mathrm{V})$ & -3.25 & -3.50 & -3.53 & -3.30 & -3.41 & -3.48 \\
\hline$\Delta I_{\mathrm{dmax}}(\%)$ & N/A & 19 & 13 & 3 & 3 & 10 \\
\hline$\Delta I_{\text {off }}(\%)$ & N/A & -1000 & -2000 & -1700 & -1400 & 280 \\
\hline$\Delta I_{\mathrm{g}}(\%)$ & N/A & -1000 & -2000 & -1800 & -500 & 800 \\
\hline$V_{\text {br }}(\mathrm{V})$ & 99 & 138 & 151 & 143 & 124 & 87 \\
\hline
\end{tabular}

${ }^{\mathrm{a} N} / \mathrm{A}$ stands for not applicable.

grown $\mathrm{SiO}_{x}$ [32] in the literature. Figure 3 summarises the change of RMS roughness as a function of the residual pressure. The RMS roughness first increases gradually from 0.55 to $0.62 \mathrm{~nm}$ as the residual pressure increases from $1 \times$ $10^{-6}$ to $5 \times 10^{-5}$ Torr, and then rapidly to $1.01 \mathrm{~nm}$ by further increases of the residual pressure to $1 \times 10^{-4}$ and $6 \times 10^{-4}$ Torr (samples D and E). Accordingly, some larger particles can be observed in Fig. 2(c), (d), and (e). Particularly, the RMS roughness for the $\mathrm{SiO}_{\mathrm{x}}$ film prepared at $6 \times 10^{-4} \mathrm{Torr}$ (sample E) is as high as $1.01 \mathrm{~nm}$, nearly twice that of sample A. The increased surface roughnesses may be related to the increased molecule collisions inside the evaporator chamber due to the introduction of oxygen molecules in the evaporation.
Nevertheless, it should be noted that the $\mathrm{SiO}_{\mathrm{x}}$ film roughness in all samples is relatively small.

The dependence of oxygen content $(\mathrm{x})$ determined by EDS on the residual oxygen pressure is shown in Fig. 3. The $x$ value of the $\mathrm{SiO}_{x}$ film deposited with no intentionally introduced oxygen is 1.10 . By changing the oxygen pressure in the chamber, films with varied stoichiometry up to $\mathrm{x}=1.71$ are produced. This is due to the oxidization of $\mathrm{SiO}$ by the introduced oxygen in the growth process [29].

Figure 4 illustrates the dependence of $n_{\mathrm{s}}$ and $\mu_{\mathrm{n}}$ of the two-dimensional gas (2DEG) in the $\mathrm{AlGaN} / \mathrm{AlN} / \mathrm{GaN}$ heterostructure on the residual oxygen pressure during the evaporation of the $\mathrm{SiO}_{\mathrm{x}}$ films. In the unpassivated sample, $n_{\mathrm{s}}$ is $9.40 \times 10^{12} \mathrm{~cm}^{-2}$. After the $\mathrm{SiO}_{\mathrm{x}}$ passivation, $n_{\mathrm{s}}$ increases and ranges from $9.80 \times 10^{12}$ to $1.08 \times 10^{13} \mathrm{~cm}^{-2}$. The increase in the 2DEG density could be due to reduced surface traps by the passivation. Another factor may be passivation induced stress in the AlGaN layer which changes the piezoelectric polarization in the $\mathrm{AlGaN} / \mathrm{AlN} / \mathrm{GaN}$ heterostructure $[33,34]$.

The Hall measurements also indicate that the electron mobility $\mu_{\mathrm{n}}$ slightly drops from $1850 \mathrm{~cm}^{2} \cdot \mathrm{V}^{-1} \cdot \mathrm{s}^{-1}$ in

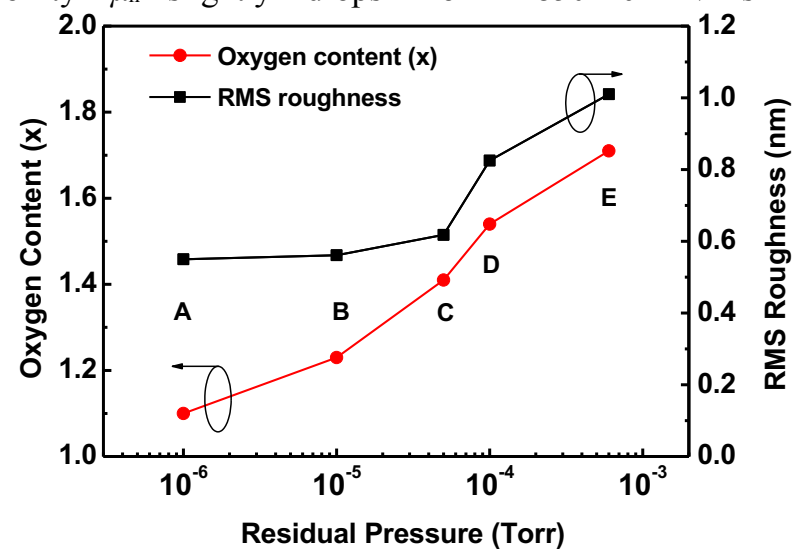

Fig. 3. Oxygen content $(\mathrm{x})$ and root-mean-square roughness of the $\mathrm{SiO}_{\mathrm{x}}$ films thermally evaporated at different residual pressures.

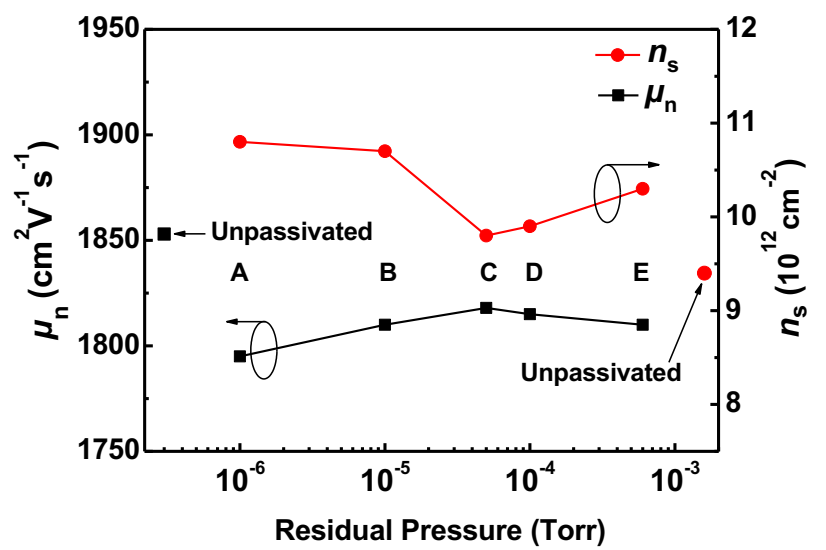

Fig. 4. $2 \mathrm{DEG}$ sheet concentration and Hall mobility of AlGaN/AlN/GaN heterostructures with $\mathrm{SiO}_{x}$ films thermally evaporated at different residual pressures (Sample A: $1 \times 10^{-6}$ Torr, B: $1 \times 10^{-5}$ Torr, C: $5 \times 10^{-5}$ Torr, D: $1 \times 10^{-4}$ Torr, E: $6 \times 10^{-4}$ Torr).

unpassivated sample to $1795-1818 \mathrm{~cm}^{2} \cdot \mathrm{V}^{-1} \cdot \mathrm{s}^{-1}$ after the $\mathrm{SiO}_{\mathrm{x}}$ passivation. This is likely due to the increased 
interface-roughness scattering and increased Coulomb scatterings in the 2DEG with higher electron sheet concentrations $[35,36]$. Overall, a larger product of $n_{\mathrm{s}} \cdot \mu_{\mathrm{n}}$ in all passivated samples (A, B, C, D and E) as compared to the unpassivated sample has been obtained, implying improved electron conduction characteristics in the $\mathrm{SiO}_{\mathrm{x}}$ passivated HEMTs.

The output characteristics in DC and pulsed modes as well as the DC-transfer characteristics of the HEMTs before and after the $\mathrm{SiO}_{\mathrm{x}}$ passivation (evaporated at $1 \times 10^{-5}$ Torr) are shown in Fig. 5. The drain current versus drain voltage $\left(I_{\mathrm{ds}}-V_{\mathrm{ds}}\right)$ characteristics were measured at the gate bias $\left(V_{\mathrm{gs}}\right)$ ranging from $+1 \mathrm{~V}$ to $-4 \mathrm{~V}$. Increases in the maximum drain current $\left(I_{\mathrm{dmax}}\right)$ and transconductance $\left(g_{\mathrm{m}}\right)$ by $13 \%$ and $20 \%$ for the passivated device are obtained when compared with the unpassivated HEMT. The $I_{\mathrm{dmax}}$ of the device without passivation is $345 \mathrm{~mA} \cdot \mathrm{mm}^{-1}$ and increases to $390 \mathrm{~mA} \cdot \mathrm{mm}^{-1}$ after $\mathrm{SiO}_{\mathrm{x}}$ passivation (at residual pressure of $1 \times 10^{-5}$ Torr), as shown in Fig. 5(a). The observed increase in carrier concentration following the deposition of $\mathrm{SiO}_{\mathrm{x}}$ passivation layer may be the key factor for the reduction in the source-drain

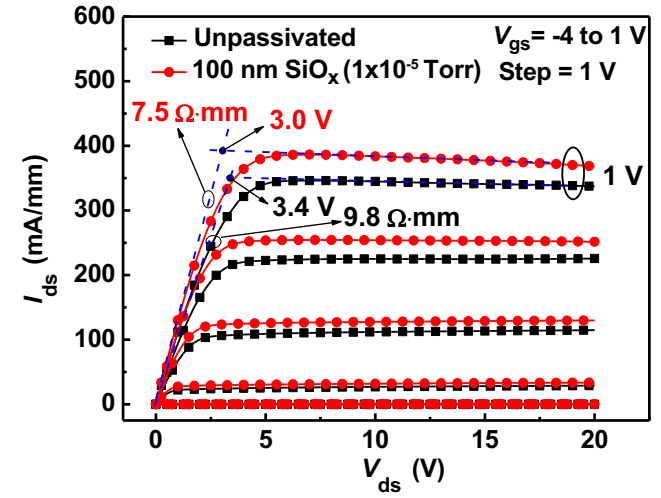

(a)

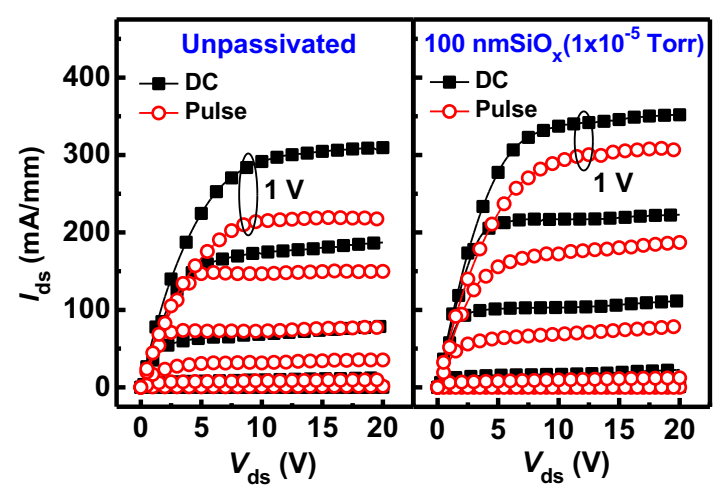

(b)

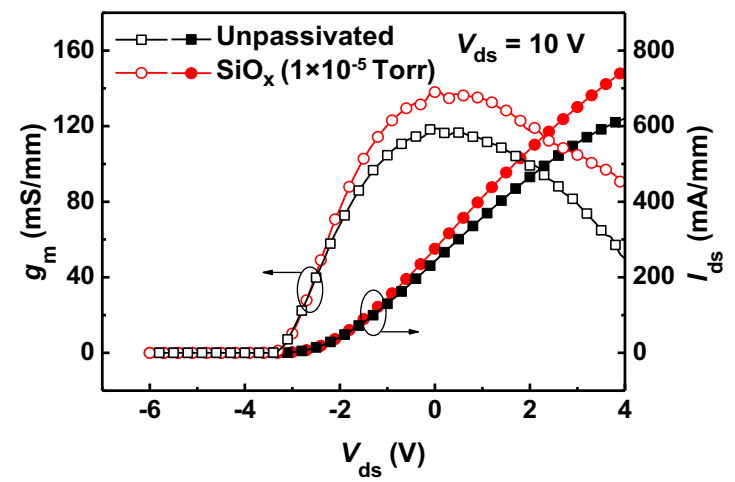

(c)

Fig. 5. (a) DC, (b) pulsed output characteristics and (c) DC-transfer characteristics of the AlGaN/AIN/GaN HEMTs before and after the $\mathrm{SiO}_{x}$ passivation thermally evaporated at $1 \times 10^{-5}$ Torr. The pulse width and pulse period were $50 \mu$ s and $100 \mathrm{~ms}$, respectively.

series resistance and increase in the drain current [37]. Figure 5(a) also illustrates the methodology to determine the on resistance $R_{\mathrm{on}}$ and knee voltage $V_{\mathrm{k}}$. The passivated device shows a knee voltage of $3.0 \mathrm{~V}$ and an on resistance of $7.5 \Omega \cdot \mathrm{mm}$, much lower than those of the unpassivated device $(3.4 \mathrm{~V}, 9.8 \Omega \cdot \mathrm{mm})$ as shown in Fig. 5(a).

The pulsed $I_{\mathrm{ds}}-V_{\mathrm{ds}}$ curves in Fig. 5(b) were measured with a pulse width of $50 \mu \mathrm{s}$ and a pulse period of $100 \mathrm{~ms}$ under quiescent biases of $V_{\mathrm{gs}}=-5 \mathrm{~V}$ and $V_{\mathrm{ds}}=0 \mathrm{~V}$. In comparison, the unpassivated device shows a drastic drain current collapse (28.2\% decrease in $\left.I_{\mathrm{dmax}}\right)$ while the HEMT passivated with film $\mathrm{B}$ (evaporated at $1 \times 10^{-5}$ Torr) has a much smaller 
collapse (11.5\%). The improvement can be explained by the reduction of surface traps discussed above [38]. The current collapse effect has also been alleviated by different degrees in other passivated devices as shown in Table I. Similarly, $g_{\mathrm{m}}$ (at $\left.V_{\mathrm{ds}}=10 \mathrm{~V}\right)$ calculated from the DC-transfer characteristics also improves from $116 \mathrm{mS} \cdot \mathrm{mm}^{-1}$ in the unpassivated device to $139 \mathrm{mS} \cdot \mathrm{mm}^{-1}$ in device with $\mathrm{SiO}_{1.23}$ passivation as shown in Fig. 5(c) and Table I. In addition, the threshold voltage $\left(V_{\text {th }}\right)$ of the passivated HEMTs decreases as compared to the unpassivated devices (also see Table I) due to the increased 2DEG concentration after $\mathrm{SiO}_{x}$ passivation $[9,39]$.

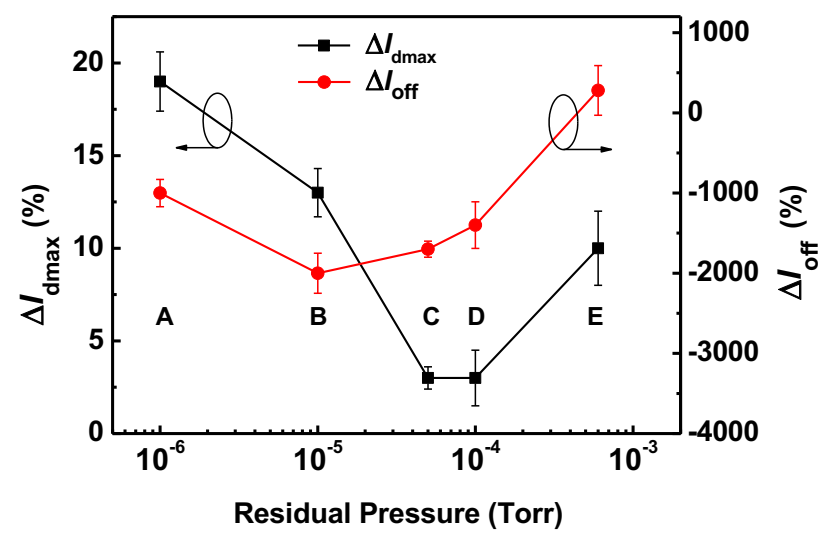

Fig. 6. Variations of maximum drain current (at $V_{\mathrm{gs}}=1 \mathrm{~V}$ ) and off-state (at $V_{\mathrm{gs}}=-6 \mathrm{~V}, V_{\mathrm{ds}}=10 \mathrm{~V}$ ) drain current of AlGaN/AlN/GaN HEMTs with $\mathrm{SiO}_{\mathrm{x}}$ passivations thermally evaporated at different residual pressures.

The changes in the maximum drain current (at $V_{\mathrm{gs}}=1 \mathrm{~V}$ ) and off-state drain current (at $V_{\mathrm{gs}}=-6 \mathrm{~V}, V_{\mathrm{ds}}=10 \mathrm{~V}$ ) in HEMTs with $\mathrm{SiO}_{x}$ passivation evaporated at different residual pressures are illustrated in Fig. 6 . The values are the averages of three devices fabricated under the same condition and the error-bars show the standard deviation of the measurements. The improvement of $I_{\mathrm{dmax}}$ varies among the different samples with different $\mathrm{SiO}_{x}$ passivations, which may be attributed to factors including the different surface trap state densities, different amount of stress in the AlGaN layer and varied $\mathrm{SiO}_{\mathrm{x}} / \mathrm{AlGaN}$ interface stoichiometry due to the passivation under different deposition conditions [40, 41]. It should be mentioned that $I_{\mathrm{dmax}}$ of all $\mathrm{SiO}_{\mathrm{x}}$ passivated devices has increased by some extent, which correlates to the improved $n_{\mathrm{s}} \cdot \mu_{\mathrm{n}}$ in all passivated samples as compared to the unpassivated sample [42-44].

The off-state and leakage characteristics of the HEMTs are often as important as the on state characterisics for high power and low noise applications [45, 46]. For instance, a correlation is known between the off-state drain current (or drain leakage current) $I_{\text {off, }}$ the gate leakage current $I_{\text {gleak }}$ and the breakdown voltage $V_{\text {br }}$ [23]. Figure 6 shows the dependence of $I_{\text {off }}$ on the residual pressure. Clearly, the drain leakage current in most passivated HEMTs is suppressed except in the film E passivated devices where the $\mathrm{SiO}_{\mathrm{x}}$ roughness is the highest. $I_{\text {off }}$ of $\mathrm{SiO}_{1.23}$ (sample B) passivated HEMTs decreases by almost a factor of 20 as compared to the unpassivated devices, which is significant. The difference in I off among the HEMTs may be caused by different densities of surface traps, $\mathrm{SiO}_{\mathrm{x}}$ roughnesses, and/or activation energies of the electron hopping conduction at the device surface [47].

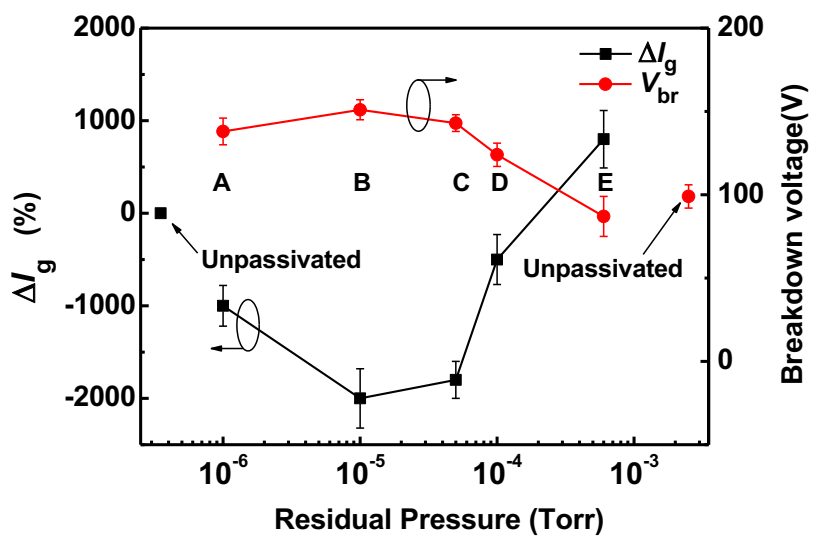

Fig. 7. Variations of gate leakage current $\left(\right.$ at $\left.V_{\mathrm{gs}}=-5 \mathrm{~V}\right)$ and off-state (at $V_{\mathrm{gs}}=$ $-6 \mathrm{~V}$ ) breakdown voltage of AlGaN/AlN/GaN HEMTs with $\mathrm{SiO}_{\mathrm{x}}$ passivations thermally evaporated at different residual pressures.

TABLE II

COMPARISON OF DEVICE CHARACTERISTICS

\begin{tabular}{cccccc}
\hline \hline Variation (\%) & $\Delta g_{\mathrm{m}}$ & $\Delta I_{\mathrm{dmax}}$ & $\Delta V_{\mathrm{br}}$ & $\Delta I_{\mathrm{off}}$ & $\Delta I_{\mathrm{g}}$ \\
\hline This work & 20 & 13 & 53 & -2000 & -2000 \\
& 24 & 34 & 56 & -1000 & -1000 \\
\multirow{2}{*}{ Reference } & Ref.[44]: & $\begin{array}{c}\text { Ref.[44]: } \\
\text { PECVD- }\end{array}$ & Ref.[9]: \\
& USPD $^{\mathrm{b}}-\mathrm{Al}_{2} \mathrm{O}_{3}$ & $\mathrm{SiN}_{\mathrm{x}}$ & & PECVD-SiN \\
\end{tabular}

${ }^{\mathrm{b}}$ USPD stands for ultrasonic spray pyrolysis deposition.

In addition to the drain leakage current, the dependence of the two-terminal (gate-source) gate leakage current (at $V_{\mathrm{gs}}=$ $-5 \mathrm{~V}), I_{\text {gleak, }}$ on the residual pressure has also been investigated. During the measurements, the source and drain were grounded and the gate current was measured as a function of the reverse gate bias. As shown in Fig. 7, a significant difference in the gate leakage current has been observed. Similar to the off-state drain current, the film B passivated devices exhibit the best gate leakage current characteristic. Igleak is nearly 20 times lower than that of the unpassivated HEMTs, which indicates a higher breakdown voltage [23]. However, the $I_{\text {gleak }}$ of the film E passivated HEMTs rises by almost one order of magnitude. Such a trend has also been observed in $\mathrm{SiO}_{2}$ passivated HEMTs by others $[9,48]$ and it will have implications for increased radio-frequency (RF) noise and reduced breakdown voltage. The surface passivation effects on the gate leakage observed for $\mathrm{SiO}_{\mathrm{x}}$ films are believed to be related to the density of interface traps between the passivation layer and the AlGaN surface [49]. It has been demonstrated that the surface related traps with an activation energy of $0.21 \mathrm{eV}$ can lead to gate leakage in GaN HEMTs [47], and surface traps can be influenced by the different passivations and/or different process conditions. Lugani et al. [50] proposed that the existence of trap assisted tunnelling can be a possible mechanism of the gate leakage current. In this study, the variation of $I_{\text {gleak }}$ may be influenced by the interface traps 
related to different $\mathrm{SiO}_{\mathrm{x}}$ roughnesses since a larger roughness may lead to larger densities of the gate leakage related interface traps [51, 52]. Moreover, oxygen vacancies in the $\mathrm{SiO}_{\mathrm{x}}$ films may act as the current leakage paths. It has been reported that adding oxygen in the sputtering gas can improve the oxide quality by introducing oxygen atoms into the film to reduce oxygen vacancies [53]. Therefore, the variation of $I_{\text {gleak }}$ in our study may be explained by the combined effect of roughness and oxygen vacancies of $\mathrm{SiO}_{\mathrm{x}}$. The oxygen vacancies play a key role at low residual pressures below $1 \times$ $10^{-5}$ Torr, while the influence of roughness becomes dominant under higher residual pressures.

The off-state breakdown characteristics of the HEMTs with different $\mathrm{SiO}_{\mathrm{x}}$ passivations have been measured as shown in Fig. 7. The gate was biased at $-6 \mathrm{~V}$ to fully pinch off the conducting channel. In order not to destroy the devices, the compliance drain current density was set to $1 \mathrm{~mA} \cdot \mathrm{mm}^{-1}$. A trend closely related to the variations of $I_{\text {off }}$ and $I_{\text {gleak }}$ has been

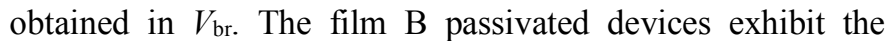
highest $V_{\text {br }}(151 \mathrm{~V})$ when compared with the unpassivated (99 V), films A (138 V), C (143 V), D (124 V), and E (87 V) passivated HEMTs, which correlates to their lowest leakage currents. It has been demonstrated that the gate leakage is closely related to the off-state breakdown voltage of GaN HEMTs [23]. The improvements of breakdown voltage in most of the passivated HEMTs are largely due to the passivation of surface trapping centers [39]. $V_{\mathrm{br}}$ of film E passivated HEMTs reduces nearly $12 \%$ as compared with the unpassivated devices, which is also in good agreement with their highest leakage currents most likely due to the largest $\mathrm{SiO}_{\mathrm{x}}$ film roughness.

Table II compares the results of $\mathrm{SiO}_{1.23}$ passivated devices in this work and the typical values published on GaN HEMTs with other passivations in literature. Even though the values of $\Delta g_{\mathrm{m}}, \Delta I_{\mathrm{dmax}}$, and $\Delta V_{\mathrm{br}}$ for our devices are slightly lower [44], the values of $\Delta I_{\text {off }}$ and $\Delta I_{\mathrm{g}}$ for our $\mathrm{SiO}_{1.23}$ passivated devices are nearly two times lower than the reported values [9], which may be due to the low ion damage and low temperature process of thermal evaporation.

\section{CONCLUSION}

In conclusion, we have investigated the suitability of $\mathrm{SiO}_{x}$ films reactively evaporated under different oxygen pressures for surface passivation of AlGaN/AlN/GaN HEMTs. Both the oxygen content and surface roughness of $\mathrm{SiO}_{\mathrm{x}}$ films varied significantly with the oxygen pressure. Due to the reduction of surface traps and possibly introduced changes in stress and piezoelectric polarization in the AlGaN layer caused by the $\mathrm{SiO}_{\mathrm{x}}$ passivation, a larger product of $n_{\mathrm{s}} \cdot \mu_{\mathrm{n}}$ was obtained in all passivated samples. Accordingly, obvious increases in $I_{\mathrm{dmax}}$ and $g_{\mathrm{m}}$ were observed. The devices passivated with $\mathrm{SiO}_{\mathrm{x}}$ deposited at $1 \times 10^{-5}$ Torr, i.e. $\mathrm{SiO}_{1.23}$, showed the lowest current collapse, lowest leakage currents as well as the best breakdown characteristics in comparison with other samples. Both $I_{\text {off }}$ and $I_{\text {gleak }}$ decreased by a factor of $\sim 20$ and $V_{\text {br }}$ increased by $52 \mathrm{~V}$ when compared with the unpassivated HEMTs. The reactively evaporated $\mathrm{SiO}_{\mathrm{x}}$ is therefore shown to be capable of providing promising low-damage surface passivation for GaN HEMTs by not only enhancing the output characteristics but also suppressing the leakage currents and increasing the breakdown voltage.

\section{ACKNOWLEDGMENTS}

This work was supported by the National Key Research and Development Program of China (Nos. 2016YFA0301200, 2016YFA0201800), National Natural Science Foundation of China (Nos. 11374185), Engineering and Physical Sciences Research Council (EPSRC) (No. EP/N021258/1), CAEP THz Science and Technology Foundation (No. CAEPTHZ201409), Key Research and Development Program of Shandong Province, China (Nos. 2016GGX104013, 2017GGX201007), Developing Foundation of CAEP (key project) (No. 2014A05011), and Suzhou Planning Projects of Science and Technology (No. SYG201616).

\section{REFERENCES}

[1] D. M. F. Medjdoub, J. Das, J. Derluyn, K. Cheng, S. Degroote, N. Vellas, C. Gaquière, M. Germain and S. Decoutere, "GaN-on-Si HEMTs above $10 \mathrm{~W} / \mathrm{mm}$ at $2 \mathrm{GHz}$ together with high thermal stability at 325 ${ }^{\circ} \mathrm{C}, "$ in the 5th European Microwave Integrated Circuits Conference (EuMIC), Paris, France, 2010, pp. 37-40.

[2] W. Shaobing, G. Jianfeng, W. Weibo, and Z. Junyun, "W-band MMIC PA with ultrahigh power density in 100-nm AlGaN/GaN Technology," IEEE Trans. Electron Devices, vol. 63, no. 10, pp. 3882-3886, 2016, doi: 10.1109/ted.2016.2597244.

[3] Y. Tang, K. Shinohara, D. Regan, A. Corrion, D. Brown, J. Wong, A. Schmitz, H. Fung, S. Kim, and M. Micovic, "Ultrahigh-speed GaN high-electron-mobility transistors with $f_{\mathrm{T}} / f_{\max }$ of $454 / 444 \mathrm{GHz}$," IEEE Electron Device Lett., vol. 36, no. 6, pp. 549-551, 2015, doi: 10.1109/led.2015.2421311.

[4] Q. Jiang, C. Liu, Y. Lu, and K. J. Chen, "1.4-kV AlGaN/GaN HEMTs on a GaN-on-SOI platform," IEEE Electron Device Lett., vol. 34, no. 3, pp. 357-359, 2013, doi: 10.1109/led.2012.2236637.

[5] A. Tarakji, G. Simin, N. Ilinskaya, X. Hu, A. Kumar, A. Koudymov, J. Yang, M. A. Khan, M. S. Shur, and R. Gaska, "Mechanism of radio-frequency current collapse in $\mathrm{GaN}-\mathrm{AlGaN}$ field-effect transistors," Appl. Phys. Lett., vol. 78, no. 15, pp. 2169-2171, 2001, doi: 10.1063/1.1363694.

[6] B. M. Green, K. K. Chu, E. M. Chumbes, J. A. Smart, J. R. Shealy, and L. F. Eastman, "The effect of surface passivation on the microwave characteristics of undoped AlGaN/GaN HEMT's," IEEE Electron Device Lett., vol. 21, no. 6, pp. 268-270, 2000, doi: 10.1109/55.843146.

[7] R. Vetury, N. Q. Zhang, S. Keller, and U. K. Mishra, "The impact of surface states on the DC and RF characteristics of AlGaN/GaN HFETs," IEEE Trans. Electron Devices, vol. 48, no. 3, pp. 560-566, 2001, doi: $10.1109 / 55.843146$

[8] Z. H. Liu, G. I. Ng, H. Zhou, S. Arulkumaran, and Y. K. T. Maung, "Reduced surface leakage current and trapping effects in AlGaN/GaN high electron mobility transistors on silicon with $\mathrm{SiN} / \mathrm{Al}_{2} \mathrm{O}_{3}$ passivation," Appl. Phys. Lett., vol. 98, no. 11, p. 113506, 2011, doi: 10.1063/1.3567927.

[9] S. Arulkumaran, T. Egawa, H. Ishikawa, T. Jimbo, and Y. Sano, "Surface passivation effects on $\mathrm{AlGaN} / \mathrm{GaN}$ high-electron-mobility transistors with $\mathrm{SiO}_{2}, \mathrm{Si}_{3} \mathrm{~N}_{4}$, and silicon oxynitride," Appl. Phys. Lett., vol. 84, no. 4, pp. 613-615, 2004, doi: 10.1063/1.1642276.

[10] S. C. Liu, C. K. Huang, and E. Y. Chang, "GaN MIS-HEMT with low dynamic on-resistance using SiON passivation," ECS Trans., vol. 72, no. 5, pp. 19-21, 2016, doi: 10.1149/07205.0019ecst.

[11] T. Hashizume, S. Ootomo, and H. Hasegawa, "Suppression of current collapse in insulated gate $\mathrm{AlGaN} / \mathrm{GaN}$ heterostructure field-effect transistors using ultrathin $\mathrm{Al}_{2} \mathrm{O}_{3}$ dielectric," Appl. Phys. Lett., vol. 83, no. 14, pp. 2952-2954, 2003, doi: 10.1063/1.1616648.

[12] S. Joglekar, M. Azize, E. J. Jones, D. Piedra, S. Gradecak, and T. Palacios, "Impact of $\mathrm{Al}_{2} \mathrm{O}_{3}$ passivation on $\mathrm{AlGaN} / \mathrm{GaN}$ nanoribbon 
high-electron-mobility transistors," IEEE Trans. Electron Devices, vol. 63, no. 1, pp. 318-325, 2016, doi: 10.1109/ted.2015.2500159.

[13] C.-S. Lee, W.-C. Hsu, H.-Y. Liu, S.-F. Chen, Y.-C. Chen, and S.-T. Yang, "Comparative studies of normally-off Al $0.26 \mathrm{Ga} 0.74 \mathrm{~N} / \mathrm{AlN} / \mathrm{GaN} / \mathrm{Si}$ high electron mobility transistors with different gate structures," Mater. Sci. Semicond. Process., vol. 66, pp. 39-43, 2017, doi: 10.1016/j.mssp.2017.03.034.

[14] A. Malmros, P. Gamarra, M. A. di Forte-Poisson, H. Hjelmgren, C. Lacam, M. Thorsell, M. Tordjman, R. Aubry, and N. Rorsman, "Evaluation of thermal versus plasma-assisted $\mathrm{ALD} \mathrm{Al}_{2} \mathrm{O}_{3}$ as passivation for InAlN/AlN/GaN HEMTs," IEEE Electron Device Lett., vol. 36, no. 3, pp. 235-237, 2015, doi: 10.1109/Led.2015.2394455.

[15] C. Liu, E. F. Chor, and L. S. Tan, "Enhanced device performance of AlGaN/GaN HEMTs using $\mathrm{HfO}_{2}$ high-k dielectric for surface passivation and gate oxide," Semicond. Sci. Technol., vol. 22, no. 5, pp. 522-527, 2007, doi: 10.1088/0268-1242/22/5/011.

[16] R. C. Fitch, D. E. Walker, K. D. Chabak, J. K. Gillespie, M. Kossler, M. Trejo, A. Crespo, L. Liu, T. S. Kang, C. F. Lo, F. Ren, D. J. Cheney, and S. J. Pearton, "Comparison of passivation layers for $\mathrm{AlGaN} / \mathrm{GaN}$ high electron mobility transistors," J. Vac. Sci. Technol. B, vol. 29, no. 6, pp. 061204, 2011, doi: 10.1116/1.3656390

[17] Y.-S. Lin, S.-F. Lin, and W.-C. Hsu, "Microwave and power characteristics of $\mathrm{AlGaN} / \mathrm{GaN} / \mathrm{Si}$ high-electron mobility transistors with $\mathrm{HfO}_{2}$ and $\mathrm{TiO}_{2}$ passivation," Semicond. Sci. Technol., vol. 30, no. 1, pp. 015016, 2015, doi: 10.1088/0268-1242/30/1/015016.

[18] B. Luo, J. W. Johnson, J. Kim, R. M. Mehandru, F. Ren, B. P. Gila, A H. Onstine, C. R. Abernathy, S. J. Pearton, A. G. Baca, R. D. Briggs, R. J. Shul, C. Monier, and J. Han, "Influence of $\mathrm{MgO}$ and $\mathrm{Sc}_{2} \mathrm{O}_{3}$ passivation on AlGaN/GaN high-electron-mobility transistors," Appl. Phys. Lett., vol. 80, no. 9, pp. 1661-1663, 2002, doi: 10.1063/1.1455692.

[19] B. P. Gila, G. T. Thaler, A. H. Onstine, M. Hlad, A. Gerger, A. Herrero, K. K. Allums, D. Stodilka, S. Jang, B. Kang, T. Anderson, C. R. Abernathy, F. Ren, and S. J. Pearton, "Novel dielectrics for gate oxides and surface passivation on GaN," Solid-State Electron., vol. 50, no. 6, pp. 1016-1023, 2006, doi: 10.1016/j.sse.2006.04.001.

[20] C.-S. Lee, W.-C. Hsu, H.-Y. Liu, T.-T. Wu, W.-C. Sun, S.-Y. Wei, and S.-M. Yu, "Investigations on MgO-dielectric GaN/AlGaN/GaN MOS-HEMTs by using an ultrasonic spray pyrolysis deposition technique," Semicond. Sci. Technol., vol. 31, no. 5, pp. 055012, 2016, doi: 10.1088/0268-1242/31/5/055012.

[21] B. J. Ansell, I. Harrison, and C. T. Foxon, "The effect of surface passivation and illumination on the device properties of AlGaN/GaN HFETs," Phys. Status Solidi (a), vol. 188, no. 1, pp. 279-282, Nov. 2001.

[22] W. Lu, V. Kumar, R. Schwindt, E. Piner, and I. Adesida, "A comparative study of surface passivation on AlGaN/GaN HEMTs," Solid-State Electron., vol. 46, no. 9, pp. 1441-1444, 2002, doi: 10.1016/S0038-1101(02)00089-8.

[23] Y. Ohno, T. Nakao, S. Kishimoto, K. Maezawa, and T. Mizutani, "Effects of surface passivation on breakdown of $\mathrm{AlGaN} / \mathrm{GaN}$ high-electron-mobility transistors," Appl. Phys. Lett., vol. 84, no. 12, pp. 2184-2186, 2004, doi: 10.1063/1.1687983.

[24] F. Zhou, H. P. Lin, L. Zhang, J. Li, X. W. Zhang, D. B. Yu, X. Y. Jiang, and Z. L. Zhang, "Top-gate amorphous IGZO thin-film transistors with a $\mathrm{SiO}$ buffer layer inserted between active channel layer and gate insulator," Curr. Appl. Phys., vol. 12, no. 1, pp. 228-232, 2012, doi: 10.1016/j.cap.2011.06.006.

[25] H.-K. Lin, H.-L. Yu, and F.-H. Huang, "An alternative passivation approach for AlGaN/GaN HEMTs," Solid-State Electronics, vol. 54, no. 5, pp. 552-556, 2010, doi: 10.1016/j.sse.2010.02.003.

[26] H. Wang, Y. Wang, G. Zhu, Q. Wang, Q. Xin, L. Han, and A. Song, "A novel thermally evaporated etching mask for low-damage dry etching," IEEE Trans. Nanotechnol., vol. 16, no. 2, pp. 290-295, 2017, doi: 10.1109/tnano.2017.2662218.

[27] L. Yang, H. Wang, X. Zhang, Y. Li, X. Chen, X. Xu, X. Zhao, and A. Song, "Thermally evaporated $\mathrm{SiO}$ serving as gate dielectric in graphene field-effect transistors," IEEE Trans. Electron Devices, vol. 64, no. 4, pp. 1846-1850, 2017, doi: 10.1109/ted.2017.2665598

[28] G. Zhu, H. Wang, Y. Wang, X. Feng, and A. Song, "Performance enhancement of AlGaN/AlN/GaN high electron mobility transistors by thermally evaporated $\mathrm{SiO}$ passivation," Appl. Phys. Lett., vol. 109, no. 11, p. 113503, 2016, doi: 10.1063/1.4962894.

[29] U. Kahler, and H. Hofmeister, "Visible light emission from $\mathrm{Si}$ nanocrystalline composites via reactive evaporation of SiO," Opt. Mater. vol. 17, no. 1-2, pp. 83-86, 2001, doi: 10.1016/s0925-3467(01)00024-6.
[30] J. Wu, Y. Chen, D. Zhou, Z. Hu, H. Xie, and C. Dong, "Sputtered oxides used for passivation layers of amorphous InGaZnO thin film transistors," Mater. Sci. Semicond. Process., vol. 29, pp. 277-282, 2015, doi: 10.1016/j.mssp.2014.04.032.

[31] L. Pang, Y. Lian, D.-S. Kim, J.-H. Lee, and K. Kim, "AlGaN/GaN MOSHEMT with high-quality gate- $\mathrm{SiO}_{2}$ achieved by room-temperature radio frequency magnetron sputtering," IEEE Trans. Electron Devices, vol. 59, no. 10, pp. 2650-2655, 2012, doi: 10.1109/ted.2012.2208463.

[32] X. Xiao, W. Deng, X. He, and S. Zhang, "a-IGZO TFTs with inductively coupled plasma chemical vapor deposited $\mathrm{SiO}_{\mathrm{x}}$ gate dielectric," IEEE Trans. Electron Devices, vol. 60, no. 8, pp. 2687-2690, 2013, doi: 10.1109/ted.2013.2266414.

[33] C. M. Jeon, and J.-L. Lee, "Effects of tensile stress induced by silicon nitride passivation on electrical characteristics of $\mathrm{AlGaN} / \mathrm{GaN}$ heterostructure field-effect transistors," Appl. Phys. Lett., vol. 86, no. 17, p. 172101, Apr. 2005, doi: 10.1063/1.1906328.

[34] S. M. Dinara, S. K. Jana, S. Ghosh, P. Mukhopadhyay, R. Kumar, A. Chakraborty, S. Bhattacharya, and D. Biswas, "Enhancement of two dimensional electron gas concentrations due to $\mathrm{Si}_{3} \mathrm{~N}_{4}$ passivation on $\mathrm{Al}_{0.3} \mathrm{Ga}_{0.7} \mathrm{~N} / \mathrm{GaN}$ heterostructure: strain and interface capacitance analysis," $A I P$ ADV., vol. 5, no. 4, p. 047136, 2015, doi: 10.1063/1.4919098

[35] A. Pérez-Tomás, M. Placidi, N. Baron, S. Chenot, Y. Cordier, J. C. Moreno, A. Constant, P. Godignon, and J. Millán, "GaN transistor characteristics at elevated temperatures,” J. Appl. Phys., vol. 106, no. 7, p. 074519, 2009, doi: 10.1063/1.3240337.

[36] M. N. Gurusinghe, S. K. Davidsson, and T. G. Andersson, "Two-dimensional electron mobility limitation mechanisms in $\mathrm{Al}_{\mathrm{x}} \mathrm{Ga}_{1-\mathrm{x}} \mathrm{N} / \mathrm{GaN}$ heterostructures," Phys. Rev. B, vol. 72, no. 4, p. 045316 , 2005, doi: 10.1103/PhysRevB.72.045316.

[37] M. Higashiwaki, N. Hirose, and T. Matsui, "Cat-CVD SiN-passivated AlGaN-GaN HFETs with thin and high Al composition barrier Layers," IEEE Electron Device Lett., vol. 26, no. 3, pp. 139-141, 2005, doi: 10.1109/led.2004.842736.

[38] T. Hashizume, "Chemistry and electrical properties of surfaces of GaN and GaN/AlGaN heterostructures," J. Vac. Sci. Technol. B, vol. 19, no. 4, pp. 1675-1681, 2001, doi: 10.1116/1.1383078.

[39] J. Bernát, P. Javorka, A. Fox, M. Marso, H. Lüth, and P. Kordoš, "Effect of surface passivation on performance of AlGaN/GaN/Si HEMTs," Solid-State Electron., vol. 47, no. 11, pp. 2097-2103, 2003, doi: 10.1016/s0038-1101(03)00238-7.

[40] V. Desmaris, J. Y. Shiu, N. Rorsman, H. Zirath, and E. Y. Chang, "Influence of oxynitride $\left(\mathrm{SiO}_{\mathrm{x}} \mathrm{N}_{\mathrm{y}}\right)$ passivation on the microwave performance of AlGaN/GaN HEMTs," Solid-State Electron., vol. 52, no. 5, pp. 632-636, 2008, doi: 10.1016/j.sse.2007.10.022.

[41] T. B. Fehlberg, J. S. Milne, G. A. Umana-Membreno, S. Keller, U. K. Mishra, B. D. Nener, and G. Parish, "Transport studies of AlGaN/GaN heterostructures of different $\mathrm{Al}$ mole fractions with variable $\mathrm{SiN}_{\mathrm{x}}$ passivation stress," IEEE Trans. Electron Devices, vol. 58, no. 8, pp. 2589-2596, 2011, doi: 10.1109/Ted.2011.2154333.

[42] R. Mehandru, B. Luo, J. Kim, F. Ren, B. P. Gila, A. H. Onstine, C. R. Abernathy, S. J. Pearton, D. Gotthold, R. Birkhahn, B. Peres, R. Fitch, J. Gillespie, T. Jenkins, J. Sewell, D. Via, and A. Crespo, "AlGaN/GaN metal-oxide-semiconductor high electron mobility transistors using $\mathrm{Sc}_{2} \mathrm{O}_{3}$ as the gate oxide and surface passivation," Appl. Phys. Lett., vol. 82, no. 15, pp. 2530-2532, 2003, doi: 10.1063/1.1567051.

[43] P. Javorka, J. Bernát, A. Fox, M. Marso, H. Lüth, and P. Kordoš, "Influence of $\mathrm{SiO}_{2}$ and $\mathrm{Si}_{3} \mathrm{~N}_{4}$ passivation on AlGaN/GaN/Si HEMT performance," Electron. Lett., vol. 39, no. 15, pp. 1155-1157, 2003, doi: 10.1049/el:20030748.

[44] B. Y. Chou, H. Y. Liu, W. C. Hsu, C. S. Lee, Y. S. Wu, W. C. Sun, S. Y. Wei, and S. M. Yu, " $\mathrm{Al}_{2} \mathrm{O}_{3}$-passivated AlGaN/GaN HEMTs by using nonvacuum ultrasonic spray pyrolysis deposition technique," IEEE Electron Device Lett., vol. 35, no. 9, pp. 903-905, 2014, doi: 10.1109/Led.2014.2333059.

[45] L. Yu-Syuan, L. Yi-Wei, and S. S. H. Hsu, "AlGaN/GaN HEMTs with low leakage current and high on/off current ratio," IEEE Electron Device Lett., vol. 31, no. 2, pp. 102-104, 2010, doi: 10.1109/LED.2009.2036576.

[46] A. V. Vertiatchikh and L. F. Eastman, "Effect of the surface and barrier defects on the AlGaN/GaN HEMT low-frequency noise performance," IEEE Electron Device Lett., vol. 24, no. 9, pp. 535-537, 2003, doi: 10.1109/LED.2003.816588.

[47] W. S. Tan, P. A. Houston, P. J. Parbrook, D. A. Wood, G. Hill, and C. R. Whitehouse, "Gate leakage effects and breakdown voltage in 
metalorganic vapor phase epitaxy AlGaN/GaN heterostructure field-effect transistors," Appl. Phys. Lett., vol. 80, no. 17, pp. 3207-3209, 2002, doi: 10.1063/1.1473701.

[48] S. Arulkumaran, T. Hibino, T. Egawa, and H. Ishikawa, "Current collapse-free i-GaN/AlGaN/GaN high-electron-mobility transistors with and without surface passivation," Appl. Phys. Lett., vol. 85, no. 23, pp. 5745-5747, 2004, doi: 10.1063/1.1830677.

[49] B. Luo, R. M. Mehandru, J. Kim, F. Ren, B. P. Gila, A. H. Onstine, C. R. Abernathy, S. J. Pearton, R. C. Fitch, J. Gillespie, R. Dellmer, T. Jenkins, J. Sewell, D. Via, and A. Crespo, "The role of cleaning conditions and epitaxial layer structure on reliability of $\mathrm{Sc}_{2} \mathrm{O}_{3}$ and $\mathrm{MgO}$ passivation on AlGaN/GaN HEMTS," Solid-State Electron., vol. 46, no. 12, pp. 2185-2190, 2002, doi: 10.1016/s0038-1101(02)00229-0.

[50] L. Lugani, M. A. Py, J. F. Carlin, and N. Grandjean, "Leakage mechanisms in InAlN based heterostructures," J. Appl. Phys., vol. 115, no. 7, p. 074506, 2014, doi: 10.1063/1.4866328.

[51] S. Arulkumaran, G. I. Ng, and Z. H. Liu, "Effect of gate-source and gate-drain $\mathrm{Si}_{3} \mathrm{~N}_{4}$ passivation on current collapse in $\mathrm{AlGaN} / \mathrm{GaN}$ high-electron-mobility transistors on silicon," Appl. Phys. Lett., vol. 90, no. 17, p. 173504, 2007, doi: 10.1063/1.2730748.

[52] F. Karouta, M. Krämer, J. J. Kwaspen, A. Grzegorczyk, P. Hageman, B. Hoex, W. M. Kessels, J. Klootwijk, E. n. Timmering, and M. Smit, "Influence of the structural and compositional properties of PECVD silicon nitride as a passivation layer for AlGaN HEMTs," ECS Transactions, vol. 16, no. 7, pp. 181-191, 2008, doi: 10.1149/1.2983174.

[53] G. Eftekhari, "Electrical conduction in rapidly annealed sputter-deposited $\mathrm{SiO}_{2}$ films (in $\mathrm{O}_{2}-\mathrm{Ar}$ atmosphere) on Si," Phys. Status Solidi (a), vol. 151, no. 1, pp. 129-133, 1995, doi: 10.1002/pssa.2211510115. 